\title{
Molecular evidence for host-parasite co-speciation between lizards and Schellackia parasites
}

\author{
The final version of this article will appear in: International Journal for Parasitology (2018), \\ https://doi.org/10.1016/j.ijpara.2018.03.003
}

\author{
Rodrigo Megía-Palma ${ }^{\text {a, }}$, Javier Martínez ${ }^{\mathrm{b}}$, José J. Cuervo ${ }^{\text {a }}$, Josabel Belliure ${ }^{\mathrm{c}}$, Octavio Jiménez-Robles ${ }^{\mathrm{d}}$, \\ Verónica Gomes ${ }^{e}$, Carlos Cabido ${ }^{\text {, }}$, Juli G. Pausas ${ }^{\mathrm{g}}$, Patrick S. Fitze ${ }^{\text {d,h }}$, José Martín ${ }^{\text {a }}$, Santiago Merino ${ }^{\text {a }}$ \\ a Departamento de Ecología Evolutiva, Museo Nacional de Ciencias Naturales (MNCN-CSIC), José Gutiérrez Abascal 2, E-28006 Madrid, Spain \\ ${ }^{\mathrm{b}}$ Departamento de Biomedicina y Biotecnología, Área de Parasitología, Facultad de Farmacia, Universidad de Alcalá de Henares, E-28805 Alcalá de Henares, Madrid, Spain \\ ${ }^{\mathrm{c}}$ Departamento de Ciencias de la Vida, Sección de Ecología, Universidad de Alcalá, E-28805 Alcalá de Henares, Madrid, Spain \\ ${ }^{\mathrm{d}}$ Departamento de Biodiversidad y Biología Evolutiva, Museo Nacional de Ciencias Naturales (MNCN-CSIC), José Gutiérrez Abascal 2, E-28006 Madrid, Spain \\ ${ }^{\mathrm{e}} \mathrm{CIBIO/InBIO}$, Centro de Investigação em Biodiversidade e Recursos Genéticos - Universidade de Évora, 7004-516 Évora, Portugal \\ ${ }^{\mathrm{f}}$ Departamento de Herpetología, Sociedad de Ciencias Aranzadi, Alto de Zorroaga 11, E-20014 San Sebastián, Spain \\ ${ }^{g}$ Centro de Investigaciones sobre Desertificación (CIDE-CSIC), Ctra. CV-315, Km 10.7 (IVIA), E-46113 Moncada, Valencia, Spain \\ ${ }^{\mathrm{h}}$ Instituto Pirenaico de Ecología (IPE-CSIC), Av. Nuestra Señora de la Victoria 16, E-22700 Jaca, Spain
}

Keywords:

Co-evolution Host-parasite interaction Lacertidae Molecular diversity Schellackia Specificity

\begin{abstract}
Current and past parasite transmission may depend on the overlap of host distributions, potentially affecting parasite specificity and co-evolutionary processes. Nonetheless, parasite diversification may take place in sympatry when parasites are transmitted by vectors with low mobility. Here, we test the co-speciation hypothesis between lizard final hosts of the Family Lacertidae, and blood parasites of the genus Schellackia, which are potentially transmitted by haematophagous mites. The effects of current dis- tributional overlap of host species on parasite specificity are also investigated. We sampled 27 localities on the Iberian Peninsula and three in northern Africa, and collected blood samples from 981 individual lizards of seven genera and 18 species. The overall prevalence of infection by parasites of the genus Schellackia was rv35\%. We detected 16 Schellackia haplotypes of the $18 \mathrm{~S}$ rRNA gene, revealing that the genus Schellackia is more diverse than previously thought. Phylogenetic analyses showed that Schellackia haplotypes grouped into two main monophyletic clades, the first including those detected in host species endemic to the Mediterranean region and the second those detected in host genera Acanthodactylus, Zootoca and Takydromus. All but one of the Schellackia haplotypes exhibited a high degree of host specificity at the generic level and $78.5 \%$ of them exclusively infected single host species. Some host species within the genera Podarcis (six species) and Iberolacerta (two species) were infected by three non-specific haplotypes of Schellackia, suggesting that host switching might have positively influ- enced past diversification of the genus. However, the results supported the idea that current host switch-ing is rare because there existed a significant positive correlation between the number of exclusive parasite haplotypes and the number of host species with current sympatric distribution. This result, together with significant support for host-parasite molecular co-speciation, suggests that parasites of the genus Schellackia co-evolved with their lizard hosts.
\end{abstract}

\section{Introduction}

Parasites depend on hosts to undergo their life cycle and Fahrenholz's rule predicts that closely related hosts are parasitized by closely related parasites due to parallel evolutionary histories

\footnotetext{
$\Uparrow$ Corresponding author.

E-mail address: rodrigo.megia@gmail.com (R. Megía-Palma).
}

(Eichler, 1948; Hafner and Nadler, 1988). Nonetheless, the capacity of parasites to invade new hosts (i.e., host switching), especially when both hosts are closely related, makes parasitism one of the most successful life strategies (Poulin and Morand, 2000; Page, 1994; Zietara and Lumme, 2002; Ricklefs et al., 2004). However, the factors that facilitate parasites to switch hosts are not clear and identifying those may be critical for parasite control in animals and humans (Poulin and Morand, 2000; Ricklefs et al., 2014).

Among heteroxenous parasites, the vector's mobility may highly influence the probability of the parasite encountering 
compatible hosts (McCoy et al., 1999; Poulin, 1999). For example, in social lizards of the genus Egernia, blood parasites are transmitted by vectors with high (mosquitoes) and low mobility (mites). Parasites transmitted by vectors with low mobility showed aggregation within social lizard groups, whereas blood parasites transmitted by dipterans were randomly distributed among lizard groups (Godfrey et al., 2006). Parasite transmission may also be favoured if intermediate hosts and vectors have similar ecological requirements (Martínez-de la Puente et al., 2011). For example, hole-nesting birds shared malarial haplotypes due to biting midges transmitted during nesting (Martínez-de la Puente et al., 2011). Thus, both the mobility of the vector and the overlapping ecological requirements of intermediate hosts and vectors are important factors favouring parasite transmission.

Additionally, host switching has been suggested to occur frequently in geographic areas with a high diversity of potential intermediate hosts, since encountering closely related potential hosts may happen more easily (hereafter referred to as the "easy encounter" hypothesis; Fallon et al., 2005; Maia et al., 2016). Evidence for this hypothesis stems from temperate regions and homeothermic animals (e.g., Martínez-de la Puente et al., 2011). However, colonisation of a new host may be dependent on a fine matching of life history traits between hosts (e.g., immune defence) and parasites (Gandon et al., 2002). For example, if the host's immune defence detects the intruding endoparasite, colonisation might be avoided. Similarly, if the parasite is not adapted to the life-history of a potential host, colonisation of this host may be hindered (Schmid-Hempel, 2008, 2009). Furthermore, parasites living in poikilothermic hosts are directly exposed to prevailing meteorological conditions (e.g., Gillett, J.D., 1974. Direct and indirect influences of temperature on the transmission of parasites from insects to man. Symposium of the British Society for Parasitology 12, 79) and to the host's thermoregulatory behaviour (Paranjpe et al., 2014), which may require particular adaptations. This might be the reason why there is little evidence supporting the "easy encounter" hypothesis in hematic coccidians that infect lizards (Maia et al., 2011, 2012, 2016). In addition, contrasting evidence to the "easy encounter" hypothesis exists from malarial parasites of birds in equatorial areas, where high host diversity is coupled with low host abundance. The latter suggests that the probability of encountering a closely related host is indeed low (i.e., a dilution effect sensu Moens and Pérez-Tris, 2016), and thus, parasites with generalist strategies that are capable of successfully infecting phylogenetically distant avian hosts will be favoured in areas with high host diversity (Moens and Pérez-Tris, 2016).

Co-evolution between hosts and parasites may occur, especially if parasites' reproductive stages depend on a single host species (Brooks, 1988; Schrenzel et al., 2005). In this sense, the evolution of host life history traits may influence the evolution of the parasite and vice versa, and therefore, co-evolution between parasites and hosts may lead to concordant phylogenetic trees with similar evolutionary patterns and co-speciation (e.g., Schrenzel et al., 2005). Detecting co-speciation among hosts and parasites requires both sampling of a large amount of host taxa, and using adequate molecular tools to infer their phylogenies (e.g., Pollock, 2002). To date, little relative evidence exists for concordant host-parasite phylogenies in comparison to the amount of existing host-parasite assemblages (Hafner and Nadler, 1988; Hafner and Page, 1995; see also Hamilton et al., 2007). One plausible hypothesis explaining the limited evidence is the "missing the boat" hypothesis. It suggests that some parasite lineages coexisting in ancestral host lineages missed the diverging host lineages, or may have become extinct once host lineages diverged (Bensch et al., 2000). An alternative explanation states that host switching took place after host diversification and that parasite diversification was the result of horizontal transmission among host lineages (Page, 1994; Zietara and Lumme, 2002; Ricklefs et al., 2004, 2014).

The area covering the Iberian Peninsula and northern Africa is a hotspot of biodiversity in the Family Lacertidae. The Iberian Peninsula, the European region with the highest lizard biodiversity, is inhabited by 28 lacertid species classified in eight genera which represent $23 \%$ of total generic diversity of the Family Lacertidae. This hotspot is ideal for testing host-parasite co-speciation and the influence of geographic overlap, because the distribution of the different lacertid species exhibits high overlap (e.g., Salvador, A., Marco, A., 2017. Enciclopedia virtual de los vertebrados españoles. Museo Nacional de Ciencias Naturales, Madrid. http:// www.vertebradosibericos.org/). As mentioned above, previous studies investigating hemoparasite-lizard assemblages provided low support for the "easy encounter" hypothesis (e.g., Maia et al., 2016). However, none of the studies directly investigated the relative importance of co-speciation versus host-switching in the evolution of hemoparasites that use lizards as final hosts. Here, we focus on the genus Schellackia (Apicomplexa: Eimeriorina: Schellackiidae) to test the co-speciation hypothesis in lizard hosts. Lizards are the final vertebrate hosts where Schellackia undergoes the sexual (and the asexual) cycle. The occurrence of cospeciation might be more probable and stronger between parasites and their final hosts (Brooks, 1988; Doležel et al., 1999; Schrenzel et al., 2005). Thus, this suggests that co-speciation between the Lacertidae (Sauropsida: Squamata) and parasites of the genus Schellackia (Apicomplexa: Coccidiasina: Eimeriorina) is more likely than between the Lacertidae and e.g. Karyolysus (Apicomplexa: Coccidiasina: Adeleorina) which undergoes sexual reproduction in invertebrate vectors (Svahn, 1975). The genus Schellackia was originally described in the Iberian Peninsula (Reichenow, 1920), but knowledge of its diversity and distribution is scarce (MegíaPalma et al., 2013, 2014).

The present study has two main objectives: (i) exploring the genetic diversity and the phylogenetic relationships of the genus Schellackia parasitizing lacertid lizard hosts in the western Mediterranean; and (ii) testing whether the diversification pattern of the genus Schellackia, a vector-borne disease, is consistent with cospeciation with their final hosts. To this end, (i) we performed a statistical test of co-speciation comparing the phylogenetic trees of Schellackia and their lizard hosts, and (ii) we tested whether the degree of sympatry among host species predicts parasite specificity. If the genus Schellackia had diverged due to co-speciation with their final hosts, we would expect tree topologies of lizards and parasites to be concordant. In contrast, if Schellackia is a generalist genus we may expect to find a negative relationship between the number of host-specific parasite haplotypes and the degree of the distributional overlap between current final host species. This would be congruent with the predictions of the "easy encounter" hypothesis (Fallon et al., 2005).

\section{Materials and methods}

\subsection{Parasite description}

The genus Schellackia is considered a heteroxenous protozoan endoparasite because its transmission to final hosts (lizards or frogs) requires an invertebrate transmitter, but both sexual and asexual reproduction (i.e., merogony, gamogony and sporogony) occur in the gut of vertebrate hosts (Upton, 2000; Telford, 2008). The haemococcidian species that belong to this genus present endogenous oocysts. The thin-walled oocysts are located in the lamina propria of the gut and contain eight naked sporozoites (Upton, 2000; Telford, 2008). In contrast to coccidians of the Suborder Eimeriorina which undergo intestinal development 
(e.g., genera Eimeria, Isospora and Caryospora), endogenous oocysts are not expelled with the faeces (Upton, 2000). Instead, sporozoites leave the oocysts and pass into the bloodstream, where they penetrate blood cells. Haematophagous invertebrates (acarines and dipterans) ingest infested blood cells and act as passive transmitters (Telford, 2008). Once the blood cell is digested in the gut of the arthropod the sporozoite stage of the parasite is released and becomes dormant (i.e., hypnozoite) within the epithelium of the invertebrate transmitter (Upton, 2000). At least for saurian hosts, transmission is accomplished once the host ingests the invertebrate that contains hypnozoites (Telford, 2008).

In Schellackia spp., a small number of morphological characteristics have been described (by bright-field microscopy) from the sporozoites found in the blood cells of the final (i.e., vertebrate) host, and most key morphological characteristics have been described from oocysts, the intestinal endogenous stage located in the final host (Reichenow, 1920; Bonorris and Ball, 1955; Rogier and Landau, 1975; Bristovetzky and Paperna, 1990; Paperna and Finkelman, 1996; Telford, 1993, 2008). The same parasite morphotype has been reported to infect different host genera. For example, Schellackia bolivari was detected in lizard hosts of the genera Psammodromus and Acanthodactylus (Reichenow, 1920). However, recent molecular analyses revealed differences in the 18S rRNA gene of Schellackia parasites infecting two host genera, suggesting that host-parasite associations might be more complex than previously thought (Megía-Palma et al., 2013, 2014).

\subsection{Sampling methods}

We collected blood samples from 981 individual lizards of 18 species belonging to the Family Lacertidae from the Iberian Peninsula and northern Africa during the years 2011-2014 (Tables 1 and 2 and supplementary .kmz file). One of these lizard species, the spiny-footed lizard (Acanthodactylus erythrurus), was the type host species of the genus Schellackia, and it was sampled at 12 localities distributed along a large part of its distribution range, including two localities in Morocco (Table 2). Specific sampling permits were obtained for each species included in this study (see Acknowledgements). All lizards were captured by noosing and bled at the base of the tail using a needle, and blood samples were collected with heparinized capillary tubes (Megía-Palma et al., 2013, 2014). Prior to blood sampling, lizards of the species Podarcis bocagei, Podarcis carbonelli, and some Iberolacerta monticola were housed in individual containers with natural light. During housing, no other lizard species were in contact with them. Blood samples were preserved in two different ways. First, we made thin blood smears that were air-dried, fixed for five minutes in absolute methanol and stained with Giemsa stain (1/10 v/v) for 40 min. Second, blood was preserved in Whatmann paper (FTA ${ }^{\circledR}$ Classic Card, Cat. No. WB12 0205; GE Healthcare UK Limited, Buckinghamshire, UK) until extraction. After blood sampling, all lizards were released in the same area where they had been captured.

\subsection{Microscopic survey of blood parasites}

We adapted the methodology described in Merino and Potti (1995), and the same researcher (R Megía-Palma) determined the presence/absence of Schellackia parasites on all slides by examining 10,000 red blood cells at $\ 000$ magnification using a light microscope. The aim of the microscopic screening was to identify individuals infected with Schellackia parasites. To differentiate Schellackia from the Subfamily Adeleorina, which are common in lizards from the western Mediterranean (Maia et al., 2012), we used the following characteristics that are specific to hemococcidia in the western Mediterranean region: (i) the presence of a single refractile body (see discussion in Megía-Palma et al., 2014); (ii) no conspicuous parasitophorous vacuole surrounding the parasite in the cytoplasm of the host cell; and (iii) no distortion of the host cell nucleus.

\subsection{Molecular detection of parasites}

We extracted DNA from lizard blood preserved on Whatman FTA cards. FTA punches were transferred to collection vials with $250 \mathrm{~mL}$ of SET buffer (0.15 M NaCl, 0.05 M Tris, 0.001 M EDTA, pH $=8)$. Immediately, SDS $20 \%(7 \mathrm{~mL})$ and proteinase $\mathrm{K}(50 \mathrm{mg})$ were added to the vials and incubated at $55{ }^{\circ} \mathrm{C}$ overnight using a thermoshaker. The next day, ammonium acetate $5 \mathrm{M}(250 \mathrm{~mL})$ was added to the vials and incubated for $30 \mathrm{~min}$ at room temper- ature. Subsequently, vials were centrifuged at $13,000 \mathrm{~g}$ for $10 \mathrm{~min}$. After removing the pellets, DNA was precipitated with ethanol and resuspended in sterile water (Megía-Palma et al., 2013). The

Table 1

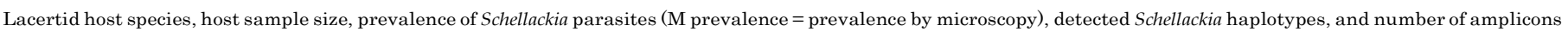
sequenced in the present study.

\begin{tabular}{|c|c|c|c|c|c|}
\hline Host species & Sample & M prevalence (\%) & PCR prevalence (\%) & Haplotypes & Amplicons \\
\hline Acanthodactylus erythrurus & 153 & 13.7 & 16.5 & $\mathrm{AeS},{ }^{\mathrm{a}} \mathrm{AeM}$ & $3,{ }^{\mathrm{a}} 6$ \\
\hline Iberolacerta aranica & 18 & - & 61 & P3 & 7 \\
\hline Iberolacerta aurelioi & 20 & - & 5 & P3 & 1 \\
\hline Iberolacerta cyreni & 157 & 1.2 & - & IB244 & 2 \\
\hline Iberolacerta monticola & 65 & - & 75.3 & IB28 & 10 \\
\hline Iberolacerta bonnali & 9 & - & 0 & - & 0 \\
\hline Lacerta schreiberi & 105 & 27.3 & 36.7 & $\mathrm{LsA},{ }^{\mathrm{a}} \mathrm{LsB}^{\mathrm{a}}$ & $9,{ }^{\mathrm{a}} 14^{\mathrm{a}}$ \\
\hline Podarcis bocagei & 11 & 18.2 & 27.2 & P3 & 2 \\
\hline Podarcis carbonelli & 6 & 0 & 0 & - & 0 \\
\hline Podarcis guadarramae & 59 & 14.5 & 32.7 & $\mathrm{PhB} 4,{ }^{\mathrm{a}} \mathrm{P} 1, \mathrm{P} 1 \mathrm{a}$ & $1,9,2$ \\
\hline Podarcis liolepis & 4 & 25 & 50 & $\mathrm{P} 1$ & 1 \\
\hline Podarcis muralis & 130 & 12 & 40 & $\mathrm{P} 1, \mathrm{P} 1 \mathrm{~b}, \mathrm{P} 2, \mathrm{P} 3$ & $2,1,4,16$ \\
\hline Podarcis vaucheri & 10 & 90 & 90 & $\mathrm{P} 3$ & 3 \\
\hline Podarcis virescens & 8 & 50 & 62.5 & $\mathrm{PhB} 4^{\mathrm{a}}$ & 4 \\
\hline Psammodromus algirus & 83 & 18 & 28 & PS1 & 10 \\
\hline Psammodromus hispanicus & 48 & 0 & 0 & - & 0 \\
\hline Timon lepidus & 13 & 38.4 & 38.4 & OC116 & 5 \\
\hline Zootoca vivipara & 82 & 4.8 & 28.8 & $\mathrm{Z} 1, \mathrm{Z} 2$ & 20,3 \\
\hline TOTAL & 981 & 22.4 & 34.8 & 17 & 109 \\
\hline
\end{tabular}

We obtained very few blood smears of I. bonnali $(n=5)$, I. aurelioi $(n=5)$, I. aranica $(n=5)$ and I. monticola (from one of the populations only $n=19)$, hence we only calculated the molecular prevalence for these host species. We screened by PCR only the two samples of I. cyreni that were positive by microscopy.

${ }^{a}$ Haplotypes detected in previous studies (Megía-Palma et al., 2013, 2014). 
Table 2

Sampling localities and Schellackia haplotypes detected at each locality. All localities are in Spain except Martil and Asilah which are in Morocco.

\begin{tabular}{|c|c|c|c|}
\hline Species & Locality & $n$ & Haplotypes \\
\hline \multirow{12}{*}{$\begin{array}{c}\text { Acanthodactylus } \\
\text { erythrurus }\end{array}$} & Ablitas (Navarra) & 8 & - \\
\hline & Leciñena (Zaragoza) & 6 & - \\
\hline & El Saler (Valencia) & 5 & - \\
\hline & Alpedrete (Madrid) & 9 & - \\
\hline & Aranjuez (Madrid) & 15 & $\mathrm{AeS},{ }^{a} \mathrm{AeM}^{\mathrm{a}}$ \\
\hline & Menasalbas (Toledo) & 8 & - \\
\hline & Béjar (Salamanca) & 4 & - \\
\hline & Matalascañas (Huelva) & 10 & - \\
\hline & Monachil (Granada) & 5 & AeM \\
\hline & Almería (Almería) & 10 & $\mathrm{AeM}$ \\
\hline & Martil, Morocco & 33 & AeM \\
\hline & Asilah, Morocco & 40 & - \\
\hline Iberolacerta aranica & Pyrenees (Lérida) & 18 & P3 \\
\hline Iberolacerta aurelioi & Pyrenees (Lérida) & 20 & P3 \\
\hline Iberolacerta bonnali & Góriz (Huesca) & 9 & - \\
\hline Iberolacerta cyreni & Peñalara (Madrid) & 157 & IB244 \\
\hline \multirow{4}{*}{$\begin{array}{l}\text { Iberolacerta } \\
\quad \text { monticola }\end{array}$} & Mirador del Fitu (Asturias) & 10 & IB28 \\
\hline & Covadonga Lakes (Asturias) & 28 & IB28 \\
\hline & Astorga (León) & $\begin{array}{l}20 \\
9\end{array}$ & 1520 \\
\hline & Vega de Liordes (León) & 18 & IB28 \\
\hline \multirow[t]{3}{*}{ Lacerta schreiberi } & Valsaín (Segovia) & 81 & $\mathrm{LsA}^{\mathrm{a}}{ }^{\mathrm{a}} \mathrm{LsB}^{\mathrm{a}}$ \\
\hline & Peñalara/Rascafría (Madrid) & 12 & - \\
\hline & Gata Mountains (Salamanca) & 12 & - \\
\hline Podarcis bocagei & Astorga (León) & 11 & P3 \\
\hline Podarcis carbonelli & Matalascañas (Huelva) & 6 & - \\
\hline Podarcis & Guadarrama Mountains (Madrid/ & 59 & P1 P1a \\
\hline guadarramae & Segovia) & & $\mathrm{PhB} 4$ \\
\hline Podarcis liolepis & La Mogorrita (Cuenca) & 4 & $\mathrm{P} 1$ \\
\hline \multirow[t]{3}{*}{ Podarcis muralis } & Somport (Huesca) & 28 & $\mathrm{P} 1, \mathrm{P} 1 \mathrm{~b}$ \\
\hline & Navacerrada/Peñalara (Madrid) & 63 & $\mathrm{P} 2, \mathrm{P} 3$ \\
\hline & Valsaín (Segovia) & 39 & P3 \\
\hline Podarcis vaucheri & Chafarinas Islands (Melilla) & 10 & P3 \\
\hline Podarcis virescens & Menasalbas (Toledo) & 8 & $\mathrm{P} 3, \mathrm{PhB} 4$ \\
\hline \multirow{7}{*}{$\begin{array}{l}\text { Psammodromus } \\
\text { algirus }\end{array}$} & Valsaín (Segovia) & 9 & PS1 \\
\hline & Aranjuez (Madrid) & 13 & PS1 \\
\hline & Chapinería (Madrid) & 10 & - \\
\hline & Menasalbas (Toledo) & 19 & PS1 \\
\hline & Cortes de Pallás (Valencia) & 14 & PS1 \\
\hline & Matalascañas (Huelva) & 8 & PS1 \\
\hline & Navacerrada (Madrid) & 10 & - \\
\hline \multirow{3}{*}{$\begin{array}{c}\text { Psammodromus } \\
\text { hispanicus }\end{array}$} & Valsaín (Segovia) & 41 & - \\
\hline & Chapinería (Madrid) & 6 & - \\
\hline & Menasalbas (Toledo) & 1 & - \\
\hline & Valsaín (Segovia) & 13 & OC116 \\
\hline \multirow[t]{2}{*}{ Zootoca vivipara } & Somport and Portalet (Huesca) & 39 & $\mathrm{Z} 1, \mathrm{Z} 2$ \\
\hline & Irún (Guipúzcoa) & 43 & $\mathrm{Z1}$ \\
\hline
\end{tabular}

${ }^{\text {a }}$ Haplotypes detected in previous studies (Megía-Palma et al., 2013, 2014).

DNA was then purified using the NZYGelpure kit (NZYTech, Lda.Genes and Enzymes, 1649-038 Lisbon, Portugal). Amplification of an $18 \mathrm{~S}$ rRNA gene fragment ( $1600 \mathrm{bp}$ ) was performed using the primer set BT-F1/EimIsoR3. These primers successfully amplified in other coccidian species (see Megía-Palma et al., 2016). Sanger sequencing was conducted on the obtained amplicons. We tested measurement reliability by performing a Pearson's correlation between parasite prevalence detected by microscopy and PCR, and using a non-parametric Wilcoxon's matched pairs test in Statistica 10.0 (Statsoft Inc., Tulsa, Oklahoma). The level of significance was 0.05 .

\subsection{Phylogenetic analyses}

Eleven new DNA sequences (18S rRNA gene; GenBank accession numbers: MG775262-MG775272) were obtained and aligned together with eight sequences closely related to Schellackia which were obtained in previous studies (Megía-Palma et al., 2013, 2014). In addition, Choleoeimeria sp. and Acroeimeria tropidura were included as outgroups. The alignment was performed using the algorithm MSAProbs that provides more accurate alignments

than ClustalW, MAFFT, MUSCLE, ProbCons and Probalign (Liu et al., 2010). The MSAProbs alignment was evaluated using the transitive consistency score (TCS). This tool identifies the most likely positions in a multiple sequence alignment (MSA) by assigning a consistency score (Chang et al., 2014). As an option, the TCS can generate a weighted MSA where each column is multiplied according to its consistency score. The more reliable columns have stronger representation, therefore improving the support of informative and reliable positions of the MSA. This appears to be particularly useful in building a phylogenetic tree (Chang et al., 2014). The weighted MSA contained 1598 positions and 22 sequences. The substitution model GTR + I + G was selected using jModelTest 2.1.4 (Darriba et al., 2012) to perform the Bayesian analysis. This analysis consisted of two runs of four chains each, with 1,000,000 generations per run. Data were collected each 100 generations and the first $25 \%$ of the generations were discarded as hurn-in. The consensus tree was obtained from the resulting 15.000 trees. The final standard deviation of the split freauencies

was lower than 0.01 . In addition, the alignment was also analysed using maximum likelihood inference (PhyML programme; Guindon et al.. 2010) and the above-mentioned substitution model. The subtree pruning and regrafting (SPR) and the nearest

neighbour interchange (NNI) tree rearrangement options were selected, and a Bayesian-like transformation of aLRT (aBayes)

was used to obtain the support for the clade (Anisimova et al., 2011). In addition, estimates of average evolutionary divergence among haplotypes were calculated using the $\mathrm{p}$-distance method and pairwise deletion in MEGA6 (Tamura et al., 2013). Standard error estimates were obtained by using a bootstrap procedure (100 replicates). We have made the datasets available in Mendeley Data (https://doi.org/10.17632/c6t47jhdhs.2).

\subsection{Host-parasite co-speciation analysis}

To test for co-speciation between parasites and hosts, the phylogenetic trees of the 15 infected lacertid species (plus Takydromus sexlineatus) and the Schellackia haplotypes were compared. The programme ParaFit (Legendre et al., 2002) implemented in CopyCat software (Meier-Kolthoff et al., 2007) was used to test the significance of a global co-speciation hypothesis. ParaFit tests the congruence of the host's and the parasite's phylogenetic trees and it also tests individual host-parasite association links. Two different analyses were performed. First, the analysis was performed using genetic distances obtained from the 514 and $1274 \mathrm{bp}$ sequences of lacertid species and Schellackia haplotypes, respectively. The genetic distances between sequences were considered as the difference in bases (percentage) between two sequences. Second, the analysis was performed using the topologies of the phylogenetic trees from Pyron et al. (2013) and of Schellackia (Fig. 1). The lacertid phylogenetic tree was based on a complete phylogeny of the Order Squamata (Pyron et al., 2013) and the relationships among the used taxa were manually coded in ParaFit. For both tests, the global null hypothesis is that host and parasite evolutions are independent. For reproducibility of the analyses, we have provided details of these datasets in Mendeley Data (https://doi.org/10.17632/c6t47jhdhs.2).

\subsection{Effect of host sympatry on Schellackia specificity}

To quantify the degree of current distributional overlap among the different lizard species included in this study, we used the SIARE database from the Spanish Herpetological Society (http:// 


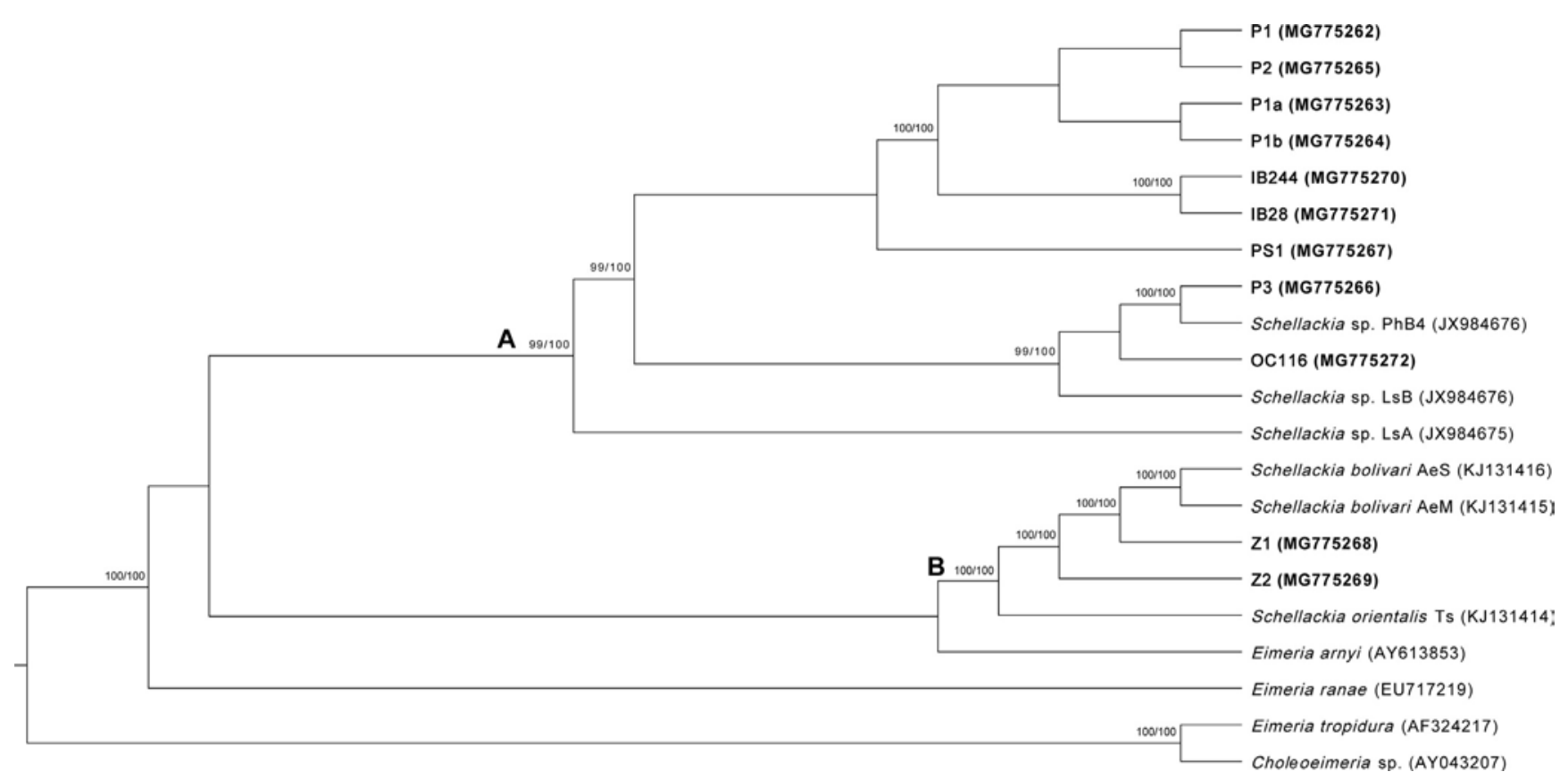

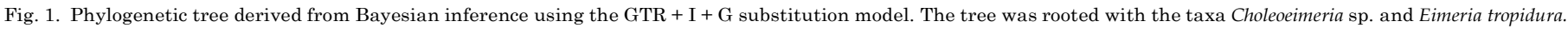

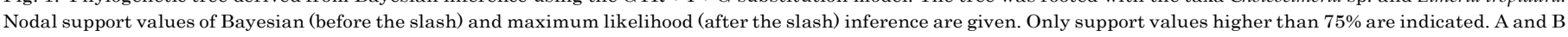

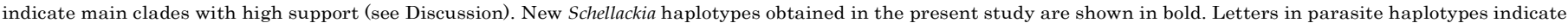
the lizard species or genus parasitized (see Table 3).

siare.herpetologica.es/bdh/distribucion). This database contains occurrences of reptile and amphibian species in a grid system with cells of $10 \$ 0 \mathrm{~km}$ that covers the whole of Spain (which is $84.6 \%$ of the Iberian Peninsula). The degree of sympatry was evaluated for each of the host species included in this study by counting the number of lizard species whose current geographic distributions overlap with the host species in focus. The degree of sympatry thus reflects the likelihood that a Schellackia haplotype may encounter a different host species. In addition, we quantify the degree of parasite specificity by the number of exclusive Schellackia haplotypes detected in each host species. This datasheet is provided as Supplementary Table S1. To test for the potential effect of the current host distributional overlap on parasite specificity, we performed a nonparametric Spearman correlation between these two variables using Statistica 10.0 (Statsoft Inc.).

\section{Results}

\subsection{Microscopic identification of parasites}

Fifteen of the 18 sampled host species were infected by Schellackia parasites. We found an overall prevalence of Schellackia infection of $22.4 \%$ by microscopic screening (minimum and maximum prevalence per population: $0-90 \%$, respectively) and $34.8 \%$ by PCR (minimum 0\%, maximum $90 \%$ ). Prevalence determined by microscopic and molecular screening were strongly correlated (Pearson's correlation: $r=0.91, P<0.0001, n=13$ ), and the values of prevalence determined by PCR were significantly higher than those determined by microscopy (Wilcoxon's matched pairs test: $Z=2.66, P=0.007, n=13$; Table 1). All blood smears that were positive for Schellackia parasites presented sporozoites that exhibited morphological characteristics similar to the type species of the genus, S. bolivari (Fig. 2). In addition, we detected the presence of parasites of the Suborder Adeleorina (namely Karyolysus sensu Haklová-Kočíková et al., 2014) which can be morphologically distinguished with a light microscope because their gametocytes are usually bigger than the sporozoites of Schellackia and host cell membranes and nuclei are distorted. In addition, parasites of the genus Karyolysus have micro- and macrogametocytes that are often surrounded by a conspicuous parasitophorous vacuole, and the cytoplasm of trophozoites show several non-stained vacuoles (Svahn, 1975; Telford, 2008).

\subsection{Molecular analyses}

We sequenced 109 amplicons obtained by PCR. The molecular characterization of the samples revealed the presence of 11 newly characterised 18S rRNA gene haplotypes closely related to the genus Schellackia (Fig. 1). Bayesian inference and maximum likelihood phylogenetic analyses produced trees with identical topologies. The sampled haplotypes grouped into two main monophyletic clades and both clades contained previously described Schellackia haplotypes, indicating that all haplotypes belong to the genus Schellackia (Fig. 1). The first clade contained Schellackia from Podarcis, Iberolacerta, Psammodromus, Lacerta and Timon (clade A), and the second clade Schellackia from Acanthodactylus, Zootoca and Takydromus (clade B). Mean (S.D.) genetic divergence was $0.0048(0.0018)$ among haplotype sequences in clade A and 0.0090 (0.0018) among haplotype sequences in clade B. Mean (S.D.) genetic divergence between clades A and B was 0.012 (0.0021). Mean (S.D.) genetic divergence among the different haplotypes was $0.0086(0.0016)$.

\subsection{Host-parasite co-speciation analyses}

There was significant support for host-parasite co-speciation, since ParaFit rejected the global null hypothesis (i.e., independent host and parasite evolutions), both when comparing the matrices of genetic distances of hosts and parasites $(P=0.001)$, and when comparing tree topologies $(P=0.004$; Table 3$)$. The global test of co-speciation remained significant (result not shown) after removing (i) host taxa with low sample sizes $(n:: ; 15)$, and (ii) host taxa 


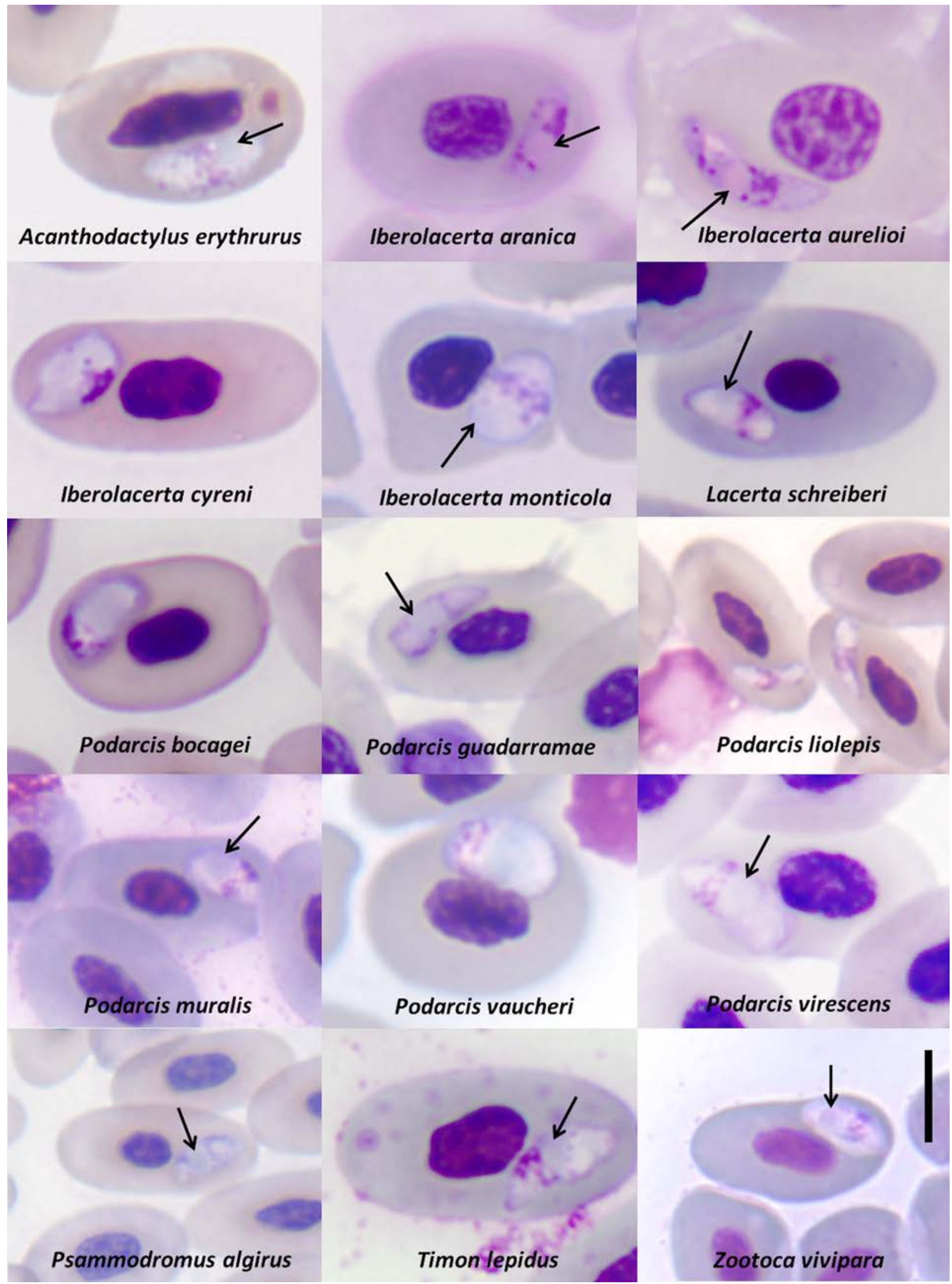

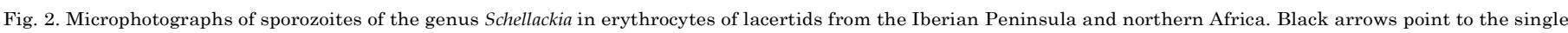
refractile body observed in the parasitic stage. All images were taken at 1000x magnification and are shown at the same scale. Scale bar $=5 \mathrm{~mm}$.

with strong influences on the global test (i.e., genus Podarcis). Individual associations of parasite haplotypes with the host species Podarcis guadarramae (with haplotype $\mathrm{PhB} 4$ ), Podarcis virescens, $P$. bocagei, Podarcis vaucheri, Zootoca vivipara (with haplotype Z1), and A. erythrurus (with both parasite haplotypes, AeM and AeS) were significant in both analyses. The association between $P$. 
Table 3

ParaFit tests including Schellackia haplotypes (Parasite) and lacertid species (Host). Probabilities were computed after 999 random permutations. The null hypothesis of the global test is that parasite evolution was independent of host evolution. In the tests of individual host-parasite associations, the null hypothesis is that the tested association was random (indiscriminate). Global tests and individual associations with $P<0.05$ are shown in bold. The ParaFit test is based on matrices of genetic distance $(\mathrm{Dmx})$ and topology of the trees.

\begin{tabular}{llll}
\hline Parasite & Host & $P$ value (Dmx) & $\begin{array}{l}\text { P value } \\
\text { (Topology) }\end{array}$ \\
\hline P1 & Podarcis guadarramae & 0.047 & 0.58 \\
$\mathrm{P} 1$ & Podarcis liolepis & 0.265 & 0.168 \\
$\mathrm{P} 1$ & Podarcis muralis & 0.059 & 0.276 \\
$\mathrm{P} 2$ & Podarcis muralis & 0.179 & 0.308 \\
$\mathrm{P} 3$ & Podarcis virescens & 0.038 & 0.010 \\
$\mathrm{P} 3$ & Podarcis bocagei & 0.037 & 0.010 \\
$\mathrm{P} 3$ & Podarcis muralis & 0.128 & 0.200 \\
$\mathrm{P} 3$ & Podarcis vaucheri & 0.039 & 0.003 \\
$\mathrm{PhB} 4$ & Podarcis guadarramae & 0.025 & 0.006 \\
$\mathrm{PhB} 4$ & Podarcis virescens & 0.039 & 0.025 \\
$\mathrm{IB} 28$ & Iberolacerta monticola & 0.596 & 0.631 \\
$\mathrm{IB} 244$ & Iberolacerta cyreni & 0.502 & 0.657 \\
$\mathrm{P} 3$ & Iberolacerta aranica & 0.476 & 0.954 \\
$\mathrm{P} 3$ & Iberolacerta aurelioi & 0.568 & 0.957 \\
$\mathrm{PS} 1$ & Psammodromus algirus & 0.570 & 0.997 \\
$\mathrm{OC} 116$ & Timon lepidus & 0.671 & 0.660 \\
$\mathrm{LsB}$ & Lacerta schreiberi & 0.260 & 0.588 \\
$\mathrm{LsA}$ & Lacerta schreiberi & 0.557 & 0.639 \\
$\mathrm{AeM}$ & Acanthodactylus erythrurus & 0.001 & 0.011 \\
$\mathrm{AeS}{ }^{\mathrm{a}}$ & Acanthodactylus erythrurus & 0.001 & 0.007 \\
$\mathrm{Z} 1$ & Zootoca vivipara & 0.045 & 0.009 \\
$\mathrm{Z} 2$ & Zootoca vivipara & 0.059 & 0.008 \\
$\mathrm{Ts}{ }^{\mathrm{b}}$ & Takydromus sexlineatus & 0.060 & 0.006 \\
$\mathrm{Global}$ Test & & 0.001 & 0.004 \\
\hline $\mathrm{S}$ & & &
\end{tabular}

${ }^{a}$ Schellackia bolivari.

b Schellackia orientalis.

guadarramae and haplotype P1 was significant when comparing the matrices of genetic distances. The associations between $Z$. vivipara and Z2, and between $T$. sexlineatus and $T \mathrm{~s}$, were significant when comparing the tree topologies (Fig. 3). In addition, we found a significant and positive relationship between the degree of sympatry (i.e., distribution overlap) of the host species and the number of exclusive Schellackia haplotypes. Spearman correlation: Rho = $0.540, P=0.02$ and weighted by the number of species: Rho $=$ $0.627, P=0.0001, n=18$ (Fig. 4).

\section{Discussion}

We detected parasites of the genus Schellackia in 15 different lizard host species, of which 11 were new host species (Table 2). The phylogenetic analyses revealed two main monophyletic clades with strong support 2:99/100; Fig. 1). Clade A grouped Schellackia haplotypes detected in lizard hosts that are either endemic to the Iberian Peninsula (Lacerta schreiberi, Iberolacerta cyreni, Iberolacerta aurelioi, Iberolacerta aranica, and I. monticola), or that have their phylogeographic origin in the western Mediterranean (Podarcis, Psammodromus, and Timon; Godinho et al., 2005; Busack and Lawson, 2006; Pinho et al., 2008; Miraldo et al., 2011). Within clade A, two well supported subclades exist. Both subclades contain Schellackia haplotypes detected in lizard hosts of phylogeographic origin in northern Africa and close to the Mediterranean basin (i.e., Psammodromus algirus and Timon lepidus) (Godinho et al., 2005; Busack and Lawson, 2006). In addition, the early branching off of haplotype LsA, which infects L. schreiberi (an Iberian endemic species), suggests a Mediterranean origin of the Schellackia parasites in clade A. In contrast, host lizard genera in clade B have diverse phylogeographic origins including Asia, northern Africa, and Europe (Lin et al., 2002; Fonseca et al., 2009; Heulin et al., 2011). It should be noted that our analyses were not based on the ancestry of the clades, but included species in the western Mediterranean only. Nonetheless, based on the phylogenetic hypothesis presented here, the early branching off of Schellackia haplotype Ts (i.e., Schellackia orientalis) which infects T. sexlineatus from Thailand, and the phylogeographic origin of T. lepidus and $L$.

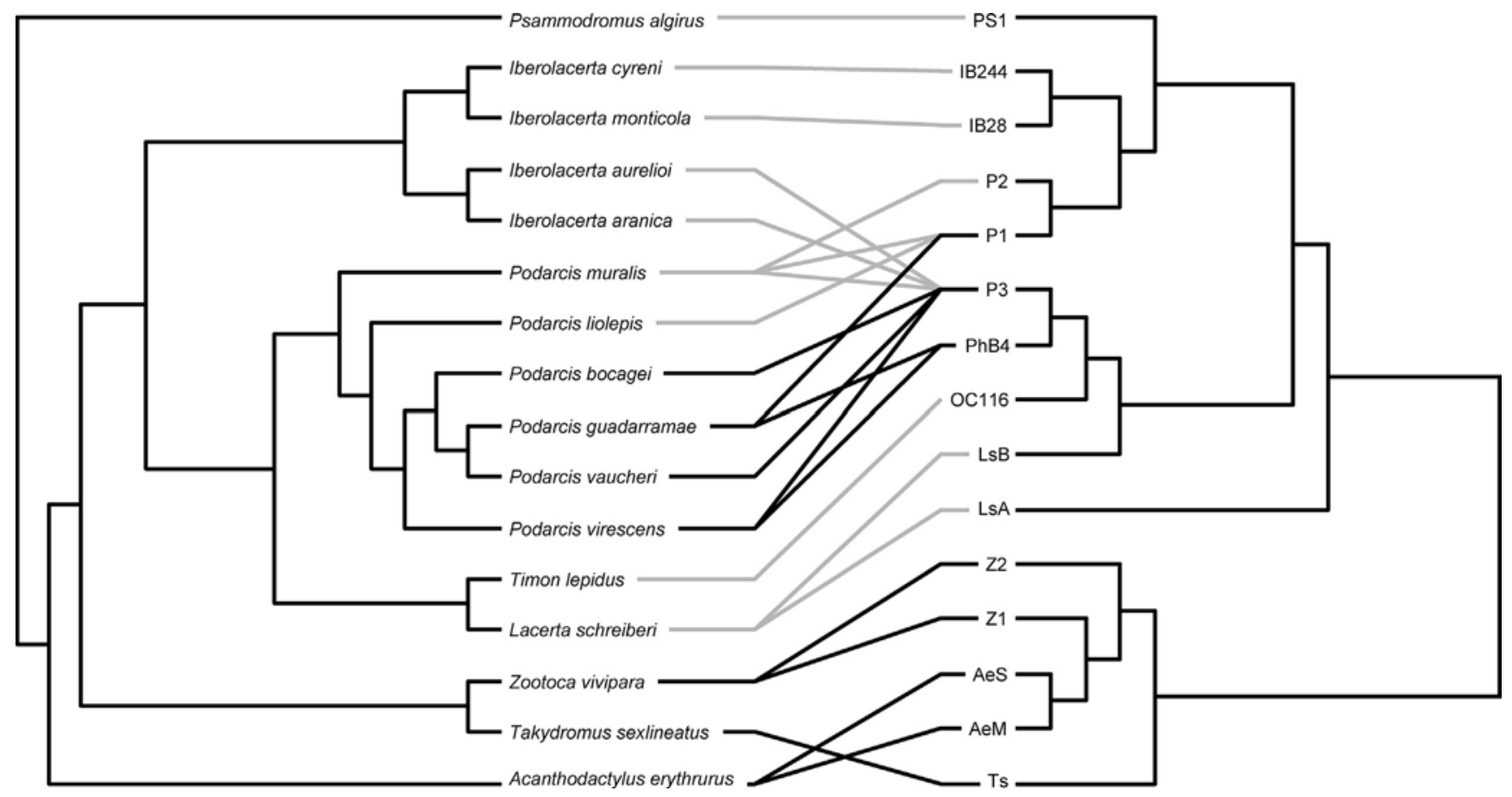

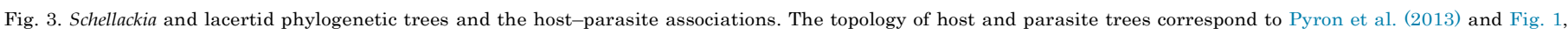

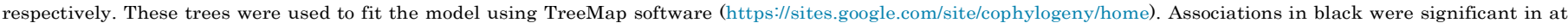
least one of the two methods (see Section 3 and Table 3). 


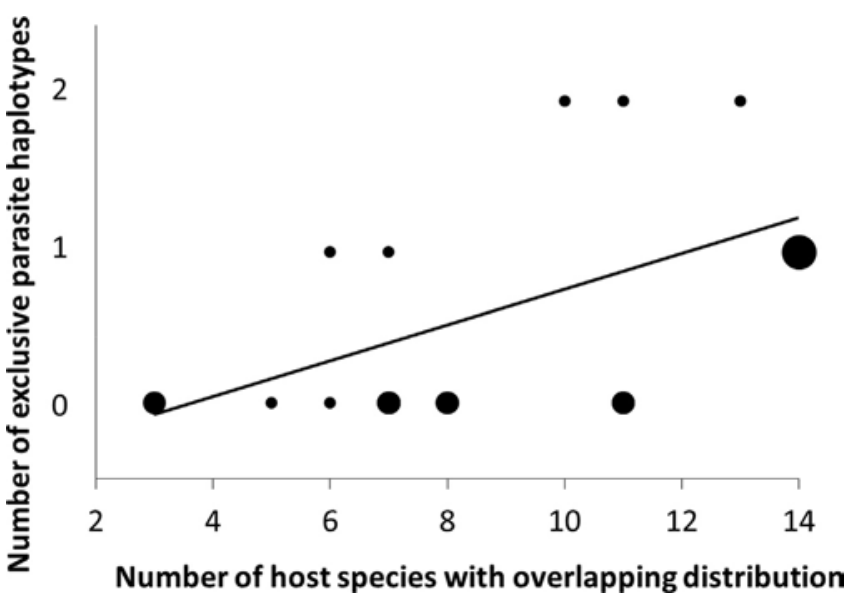

Fig. 4. Relationship between the number of exclusive Schellackia haplotypes detected per host and the number of host species with overlapping distributions (18 lizard species). Dot sizes correspond to sample sizes: small dots, $n=1$ species; medium-sized dots, $n=2$ species; large dots, $n=3$ species. The regression line was drawn to facilitate visualisation of the relationship.

schreiberi is congruent with a Mediterranean origin of Schellakia, and migration to Asia thanks to its specificity with the genus Takydromus that colonised Asia from the Mediterranean (Lin et al., 2002; Pyron et al., 2013).

Most of the detected parasite haplotypes showed high host specificity at the generic level except haplotype P3 that was found in Podarcis ( $P$. bocagei, Podarcis muralis, $P$. vaucheri, and $P$. virescens) and Iberolacerta (I. aranica and I. aurelioi). Significant individual associations of haplotype P3 with host species existed in Podarcis (e.g., $P$. bocagei, $P$. vaucheri, and $P$. virescens) but not in Iberolacerta $(P>0.45)$. This suggests that haplotype P3 might have switched recently from Podarcis to Iberolacerta. In addition to haplotype P3, two more parasite haplotypes were found in two or more host species. Haplotype P1 was present in Podarcis liolepis, P. muralis, and $P$. guadarramae, whereas haplotype $\mathrm{PhB} 4$ was detected in $P$. guadarramae and $P$. virescens (Fig. 3). The remaining Schellackia haplotypes (i.e., $78.5 \%$ of them) were detected in single host species, and several individual associations were significant (haplotypes AeM and AeS infecting A. erythrurus, haplotypes Z1 and Z2 infecting Z. vivipara, and haplotype $T$ s infecting $T$. sexlineatus; Fig. 3). Moreover, several of the parasite haplotypes were consistently infecting specific host species despite having been sampled at different localities separated by hundreds of kilometres (e.g., PS1 ex $P$. algirus in five localities, AeM ex A. erythrurus in four localities, IB28 ex I. monticola in four localities, and Z1 ex Z. vivipara in three localities). The presence of different parasite haplotypes with strong host specificity, despite high geographic overlap of the host species, points to the existence of independent parasite populations that do not interbreed, and which may have been associated with their hosts for much of their evolutionary history (Hoberg et al., 1997; Bensch et al., 2000; Ricklefs et al., 2004; see also Bensch et al., 2004). Furthermore, the high genetic similarity (299\%) among most Schellackia haplotypes suggests that they might have diverged recently (Schrenzel et al., 2005; but see Bensch et al., 2004). However, mutations in specific regions of the ribosomal genes might be more important for differentiation of independent coccidian populations than the number of base substitutions per se (Mugridge et al., 2000).

Despite the high host specificity detected, the analyses suggest that past host switching, rather than co-speciation, may explain some of the Schellackia-Lacertidae associations. For example, although the host genus Psammodromus is a basal taxon in the phylogeny of the Lacertidae (Pyron et al., 2013), the parasite haplotype that infects this host genus, PS1, is not a basal taxon of clade A (Fig. 1). This suggests that PS1 colonised P. algirus after host divergence, which may explain the lack of evidence for co- $^{-}$ speciation with $P$. algirus. The high host specificity and the detected colonisation of new hosts suggest that host switching might have been favoured under certain ecological circumstances in the past. However, given the repeated climate-induced distributional shifts of lacertids inhabiting the western Mediterranean (e.g., Gómez and Lunt, 2007), elucidating the conditions that might have favoured host switching events in past scenarios would be too speculative. Moreover, the analyses revealed little evidence for current host switching. First, as mentioned above, $78.5 \%$ of the parasite haplotypes infected single host species. Second, and perhaps more important, the correlation between the number of detected exclusive Schellackia haplotypes and the degree of current sympatry of host species was positive, whereas a negative correlation would have suggested current host switching. The positive relationship can only be explained by strict host-parasite cospeciation, since a generalist parasite would be able to infect more host species when more host species overlap geographically (e.g., Moens and Pérez-Tris, 2016). For example, in the sampling locality in the Province of Segovia (Valsaín, Spain) we collected parasite samples from four different host genera (Lacerta, Timon, Podarcis and Psammodromus) that lived in sympatry; nevertheless all detected Schellackia haplotypes infected one single host species. Thus, our results on the Schellackia-Lacertidae system cannot be explained by the "easy encounter" hypothesis (Fallon et al., 2005), because evidence for current host switching is limited. This finding is in line with previous studies that uncovered a high diversity of parasite haplotypes in areas with high abundances of closely related lizard hosts (e.g., Maia et al., 2016; Megía-Palma et al., 2017).

The high specificity of parasite haplotypes revealed in the western Mediterranean and the positive correlation between the number of specific parasite haplotypes and the degree of current sympatry, strongly contrasts with studies of avian malaria. In these studies, the proportion of malarial generalist haplotypes was higher in regions with high avian (i.e., intermediate host) diversity (Bensch et al., 2000; Ricklefs et al., 2004, 2014; Martínez-de la Puente et al., 2011; Moens and Pérez-Tris, 2016). The process of species formation among the malaria parasites of avian hosts predominantly occurs in allopatry and involves host expansion prior to local host-parasite co-speciation (Ricklefs et al., 2004, 2014), whereas the genetic isolation of the lizard parasites prior to their genetic divergence might necessarily occur in sympatry. Nonetheless, mosquitoes of the genera Aedes and Culex are potential transmitters of Schellackia parasites in eastern Mediterranean lizards (Bristovetzky and Paperna, 1990). If dipterans could also transmit Schellackia parasites in the western Mediterranean, the potentially high mobility of these transmitters might favour host switching events in the region. However, the parasite interchange seems to be rare at present, and parasite specialisation could be promoting the diversification of the genus Schellackia. Alternatively, mosquitoes might play a minor role as transmitters in the region and other transmitters with less mobility (e.g., haematophagous mites) would also contribute to the isolation of Schellackia haplotypes in specific hosts. In this sense, mites of the genus Ophionyssus (Acari: Mesostigmata: Macronyssidae) were originally described as transmitters of Schellackia (Reichenow, 1920).

In summary, this study shows: (i) that the haplotype diversity of Schellackia in the Family Lacertidae is higher than previously thought, (ii) that Schellackia exhibits a high degree of host-parasite specificity, (iii) evidence for co-speciation between poikilothermic final hosts and their haemococcidian parasites, (iv) host switching occurred in the past, and (v) host switching among hosts may 
currently exist in only $20 \%$ of the parasite haplotypes suggesting that, at present, host switching is not a common event.

\section{Acknowledgements}

We want to thank all the people provided accessible to lizard specimens from their research projects to take blood samples, or contributed by capturing lizards. C. Monasterio, W. Beukema, R. Barrientos, M. Peso, F. Ferri-Yáñez, R. García-Roa, J. Ortega and X. Santos contributed to sampling of lizards for this study. Dr. S. Fahd provided logistical support for field work in Morocco. Field stations "El Ventorrillo" and "Refugio Nacional de Caza de las Islas Chafarinas" provided logistical support. Ministerio de Economía y Competitividad and European Regional Development Fund (MINECO/ FEDER) provided financial support (CGL2012-40026-C02-01 and CGL2015-67789-C2-1-P to SM; CGL2012-40026-C02-02 to J. Martínez; CGL2015-64086-P to JGP; CGL2014-53523-P to J. Martín; CGL2008-01522, CGL2012-32459, and CGL2016-76918 to PSF). Partial support to sample in the Guadarrama Mountains was provided to OJR by project CGL2011-30393 conceded to I. de la Riva. Ministerio de Educación, Cultura y Deporte and the European Regional Development Fund (MEC/FEDER) funded JJC and JB (grant CGL2008-00137/BOS). MEC also funded RM-P (BES-2010-038427). The study was conducted under licenses from all involved authorities (numbers: 10/033298.9/13, 10/373043.9/12, 10/380311.9/12, 10/315072.9/11, 10/040449.9/13, 2012/272, 372/2013-VS (FAU13_038), DGMEN/SEN/avp_13_025_aut, Biod/MLCE-68564, EP/CYL/101/2013, EP/SG/625/2011, EP/SG/213/2013, SGYB/EF/FJRH Re-9H/13, INAGA/5000201/24/2013/04434, CSVZ5-4ZBJN-02QA1DYREG, EHV/24/2010/105-106, LCE/mp24/2012/426, 276/ HCEFLCD/DLCDPN/DPRN/CFF, 500201/24/2013/5692(1098), 2013/025426(74/CS/13), MCI-CGL2011-24150/BOS. The authors have no competing interests to declare and have no conflicts of interest.

Appendix A. Supplementary data

There is a supplementary data associated with this article .These data include Google maps of the most important areas described in this article.

\section{References}

Anisimova, M., Gil, M., Dufayard, J.F., Dessimoz, C., Gascuel, O., 2011. Survey of branch support methods demonstrates accuracy, power, and robustness of fast likelihood-based approximation schemes. Syst. Biol. 60, 685-699.

Bensch, S., Pérez-Tris, J., Waldenström, J., Hellgren, O., 2004. Linkage between nuclear and mitochondrial DNA sequences in avian malaria parasites: Multiple cases of cryptic speciation? Evolution 58 (7), 1617-1621.

Bensch, S., Stjernman, M., Hasselquist, D., Östman, Ö., Hanson, B., Westerdahl, H., Pinheiro, R.T., 2000. Host specificity in avian blood parasites: a study of Plasmodium and Haemoproteus mitochondrial DNA amplified from birds. Proc. R. Soc. Lond. B 267, 1583-1589.

Bonorris, J.S., Ball, G.H., 1955. Schellackia occidentalis n. sp., a blood-inhabiting coccidia found in lizards in Southern California. J. Protozool. 2, 31-34.

Bristovetzky, M., Paperna, I., 1990. Life cycle and transmission of Schellackia cf. agamae, a parasite of the starred lizard Agama stellio. Int. J. Parasitol. 20, 883- 892.
Brooks, D.R., 1988. Macroevolutionary comparisons of host and parasite phylogenies. Annu. Rev. Ecol. Syst. 19, 235-259.

Busack, S.D., Lawson, R., 2006. Historical biogeography, mitochondrial DNA, and allozymes of Psammodromus algirus (Lacertidae): a preliminary hypothesis. Amphibia-Reptilia 27, 181-193.

Chang, J.M., Di Tommaso, P., Notredame, C., 2014. TCS: a new multiple sequence alignment reliability measure to estimate alignment accuracy and improve phylogenetic tree reconstruction. Mol. Biol. Evol. 31, 1625-1637.

Darriba, D., Taboada, G.L., Doallo, R., Posada, D., 2012. jModelTest 2: more models, new heuristics and parallel computing. Nat. Methods 9, 772.

Doležel, D., Koudela, B., Jirkuº, M., Hypša, V., Oborník, M., Voty' pka, J., Modry', D., Šlapeta, J.R., Lukeš, J., 1999. Phylogenetic analysis of Sarcocystis spp. Of mammals and reptiles supports the coevolution of Sarcocystis spp. with their final hosts. Int. J. Parasitol. 29, 795-798.

Eichler, W., 1948. Some rules in ectoparasitism. J. Nat. Hist. $1,588-598$.

Fallon, S.M., Bermingham, E., Ricklefs, R.E., 2005. Host specialization and geographic localization of avian malarial parasites: a regional analysis in the Lesser Antilles. Am. Nat. $165,466-480$.

Fonseca, M.M., Brito, J.C., Paulo, O.S., Carretero, M.A., Harris, D.J., 2009. Systematic and phylogeographical assessment of the Acanthodactylus erythrurus group (Reptilia: Lacertidae) based on phylogenetic analyses of mitochondrial and nuclear DNA. Mol. Phylogenet. Evol. 51, 131-142.

Gandon, S., Agnew, P., Michalakis, Y., 2002. Coevolution between parasite virulence and host life-history traits. Am. Nat. 160, 374-388.

Godfrey, S.S., Bull, C.M., Murray, K., Gardner, M.G., 2006. Transmission mode and distribution of parasites among groups of the social lizard Egernia stokesii. Parasitol. Res. 99, $223-230$.

Godinho, R., Crespo, E.G., Ferrand, N., Harris, D.J., 2005. Phylogeny and evolution of the green lizards, Lacerta spp. (Squamata: Lacertidae) based on mitochondrial and nuclear DNA sequences. Amphibia-Reptilia 26, 271-285.

Gómez, A., Lunt, D.H., 2007. Refugia within refugia: patterns of phylogeographic concordance in the Iberian Peninsula. In: Weiss, S., Ferrand, N. (Eds.), Phylogeography of Southern European Refugia. Springer, Netherlands, Dordrecht, pp. $155-188$.

Guindon, S., Dufayard, J.F., Lefort, V., Anisimova, M., Hordijk, W., Gascuel, O., 2010. New algorithms and methods to estimate maximum-likelihood phylogenies: assessing the performance of PhyML 3.0. Syst. Biol. 59, 307-321.

Hafner, M.S., Page, R.D.M., 1995. Molecular phylogenies and host parasite cospeciation: gophers and lice as a model system. Philos. Trans. R. Soc. Lond. B 349, 77-83.

Hafner, M.S., Nadler, S.A., 1988. Phylogenetic trees support the coevolution of parasites and their hosts. Nature 332, 258259 .

Haklová-Koc íková, B., Hižn anová, A., Majláth, I., Racka, K., Harris, D.J., Földvári, G., Tryjanowski, P., Kokošová, 
N., Malceková, B., Majláthová, V., 2014. Morphological and molecular characterization of Karyolysus - a neglected but common parasite infecting some European lizards. Parasite Vector 7, 1-12.

Hamilton, P.B., Gibson, W.C., Stevens, J.R., 2007. Patterns of co-evolution between trypanosomes and their hosts deduced from ribosomal RNA and protein-coding gene phylogenies. Mol. Phylogenet. Evol. 44, 15-25.

Heulin, B., Surget-Grova, Y., Sinervo, B., Miles, D., Guiller, A., 2011. Dynamics of haplogroup frequencies and survival rates in a contact zone of two mtDNA lineages of the lizards Lacerta vivipara. Ecography 34, 436-447.

Hoberg, E.P., Brooks, D.R., Siegel-Causey, D., 1997. Hostparasite co-speciation: history, principles, and prospects. In: Clayton, D.H., Moore, J. (Eds.), Host- parasite Evolution: General Principles and Avian Models. Oxford University Press, Oxford, UK, pp. 215-235.

Legendre, P., Desdevises, Y., Bazin, E., 2002. A statistical test for host-parasite coevolution. Syst. Biol. 51, 217-234.

Lin, S.M., Chen, C.A., Lue, K.Y., 2002. Molecular phylogeny and biogeography of the grass lizards genus Takydromus (Reptilia: Lacertidae) of East Asia. Mol. Phylogenet. Evol. 22, 276-288.

Liu, Y., Schmidt, B., Maskell, D.L., 2010. MSAProbs: multiple sequence alignment based on pair hidden Markov models and partition function posterior probabilities. Bioinformatics 26, 1958-1964.

Maia, J.P., Harris, D.J., Carranza, S., Gómez-Díaz, E., 2016. Assessing the diversity, host-specificity and infection patterns of apicomplexan parasites in reptiles from Oman, Arabia. Parasitology 143, 1730-1747.

Maia, J.P.M., Harris, D.J., Perera, C.A., 2011. Molecular survey of Hepatozoon species in lizards from North Africa. J. Parasitol. 97, 513-517.

Maia, J.P.M.C., Perera, A., Harris, D.J., 2012. Molecular survey and microscopic examination of Hepatozoon Miller, 1908 (Apicomplexa: Adeleorina) in lacertid lizards from the western Mediterranean. Folia Parasit. 59, 241-248.

Martínez-de la Puente, J., Martínez, J., Rivero-de Aguilar, J., Herrero, J., Merino, S., 2011. On the specificity of avian blood parasites: revealing specific and generalist relationships between haemosporidians and biting midges. Mol. Ecol. 20, 3275-3287.

McCoy, K.D., Boulinier, T., Chardine, J.W., Danchin, E., Michalakis, Y., 1999. Dispersal and distribution of the tick Ixodes uriae within and among seabird host populations: the need for a population genetic approach. J. Parasitol. 85, 196202.

Megía-Palma, R., Martínez, J., Merino, S., 2013. Phylogenetic analysis based on $18 \mathrm{~S}$ rRNA gene sequences of Schellackia parasites (Apicomplexa: Lankesterellidae) reveals their close relationship to the genus Eimeria. Parasitology 140, 11491157.

Megía-Palma, R., Martínez, J., Merino, S., 2014. Molecular characterization of hemococcidia genus Schellackia (Apicomplexa) reveals the polyphyletic origin of the family Lankesterellidae. Zool. Scr. 43, 304-312.

Megía-Palma, R., Martínez, J., Nasri, I., Cuervo, J.J., Martín, J., Acevedo, I., Belliure, J., Ortega, J., García-Roa, R., Selmi, S., Merino, S., 2016. Phylogenetic relationships of Isospora,
Lankesterella, and Caryospora species (Apicomplexa: Eimeriidae) infecting lizards. Org. Divers. Evol. 16, 275-288.

Megía-Palma, R., Martínez, J., Paranjpe, D., D’Amico, V., Aguilar, R., Palacios, M.G., Cooper, R., Ferri-Yáñez, F., Sinervo, B., Merino, S., 2017. Phylogenetic analyses reveal that Schellackia parasites (Apicomplexa) detected in American lizards are closely related to the genus Lankesterella: is the range of Schellackia restricted to the Old World? Parasite Vector 10, 470.

Meier-Kolthoff, J.P., Auch, A.F., Huson, D.H., Göker, M., 2007. COPYCAT: co- phylogenetic analysis tool. Bioinformatics 23, 898-900.

Merino, S., Potti, J., 1995. High prevalence of hematozoa in nestlings of a passerine species, the pied flycatcher, Ficedula hypoleuca. Auk 112, 1041-1043.

Miraldo, A., Hewitt, G.M., Paulo, O.S., Emerson, B.S., 2011. Phylogeography and

demographic history of Lacerta lepida in the Iberian Peninsula: multiple refugia, range expansions and secondary contact zones. BMC Evol. Biol. 11, 170.

Moens, M., Pérez-Tris, J., 2016. Discovering potential sources of emerging pathogens: South America is a reservoir of generalist avian blood parasites. Int. J. Parasitol. 46, 41-49.

Mugridge, N.B., Morrison, D.A., Jakel, T.J., Heckeroth, A.R., Tenter, A.M., Johnson, A. M., 2000. Effects of sequence alignment and structural domains of ribosomal DNA on phylogeny reconstruction for the protozoan family Sarcocystidae. Mol. Biol. Evol. 17, 1842-1853.

Page, R.D.M., 1994. Parallel phylogenies: Reconstructing the history of host- parasite assemblages. Cladistics 10, 155-173.

Paperna, I., Finkelman, S., 1996. Schellackia ptyodactyli sp. n. of the fan-footed gecko Ptyodactylus hasselquistii from the rift escarpment of the lower Jordan Valley. Folia Parasitol. 43, $161-172$.

Paranjpe, D.A., Medina, D., Nielsen, E., Cooper, R.D., Paranjpe, S.A., Sinervo, B., 2014. Does thermal ecology influence dynamics of side-blotched lizards and their microparasites? Am. Zool. 54, 108-117.

Pinho, C., Ferrand, N., James, D., 2008. Non-equilibrium estimates of gene flow inferred from nuclear genealogy suggest that Iberian and North African wall lizards (Podarcis spp.) are an assemblage of incipient species. BMC Evol. Biol. 8, 63.

Pollock, D.D., 2002. Genomic biodiversity, phylogenetics, and coevolution in proteins. Appl. Bioinformatics 1, 81-92.

Poulin, R., 1999. Parasitism and shoal size in juvenile sticklebacks: conflicting selection pressures from different ectoparasites? Ethology 105, 959-968.

Poulin, R., Morand, S., 2000. The diversity of parasites. Q. Rev. Biol. 75, 277-293.

Pyron, A.A., Burbrink, F.T., Wiens, J.J., 2013. A phylogeny and revised classification of Squamata, including 4161 species of lizards and snakes. BMC Evol. Biol. 13, 93.

Reichenow, E., 1920. Der Entwicklungsgang der Hämococcidien Karyolysus und

Schellackia nov. gen. Sitzungsber. Ges. Naturf. Freunde Berlin 10, 440-447.

Ricklefs, R.E., Fallon, S.M., Bermingham, E., 2004.

Evolutionary relationships, cospeciation, and host switching in 
avian malaria parasites. Syst. Biol. 53, 111-119.

Ricklefs, R.E., Outlaw, D.C., Svensson-Coelho, M., Medeiros, M.C.I., Ellis, V.A., Latta, S., 2014. Species formation by host shifting in avian malaria parasites. Proc. Natl. Acad. Sci. USA 111, 14816-14821.

Rogier, É., Landau, I., 1975. Description de Schellackia golvani n. sp. (Lankesterellidae), parasite de Lézards de Guadaloupe. Bull. Mus. Natl. Hist. Nat. Zool. 194, 91-97.

Schmid-Hempel, P., 2008. Parasite immune evasion: a momentous molecular war.

Trends. Ecol. Evol. 23, 318-326.

Schmid-Hempel, P., 2009. Immune defence, parasite evasion strategies and their relevance for "macroscopic phenomena" such as virulence. Philos. Trans. R. Soc. Lond. B 364, 85-98.

Schrenzel, M.D., Maalouf, G.A., Gaffney, P.M., Tokarz, D., Keener, L.L., McClure, D., Griffey, S., McAloose, D., Rideout, B.A., 2005. Molecular characterization of isosporoid coccidia (Isospora and Atoxoplasma spp.) in passerine birds. J.

Parasitol. 91, 635-647.

Svahn, K., 1975. Blood parasites of the genus Karyolysus (Coccidia, Adeleidae) in Scandinavian lizards. Description and life cycle. Norw. J. Zool. 23, 277-295.

Tamura, K., Stecher, G., Peterson, D., Filipski, A., Kumar, S., 2013. MEGA6: Molecular evolutionary genetics analysis, version 6.0. Mol. Biol. Evol. 30, 2725-2729.

Telford Jr., S.R., 1993. A species of Schellackia (Apicomplexa: Lankesterellidae) parasitising east and southeast Asian lizards. Syst. Parasitol. 25, 109-117.

Telford Jr., S.R., 2008. Hemoparasites of the Reptilia. Color Atlas and Text. CRC Press, Boca Raton, Florida.

Upton, S.J., 2000. The illustrated guide to the Protozoa vol. 1, 318-339.

Zietara, M.S., Lumme, J., 2002. Speciation by host switch and adaptive radiation in a fish parasite genus Gyrodactylus (Monogenea, Gyrodactylidae). Evolution 56, 2445-2458. 